\title{
17Beta-estradiol Stimulates Glucose Uptake Through Estrogen Receptor and AMP-activated Protein Kinase Activation in C2C12 Myotubes (Korean J Obes 2016;25:190-6)
}

*Corresponding author Seong-Kyu Lee

http://orcid.org/0000-0002-5999-7656

Department of Biochemistry-Molecular Biology, School of Medicine, Eulji University, 77 Gyeryong-ro 771 beon-gil, Jung-gu, Daejeon 34824, Korea

Tel: +82-42-259-1642

Fax +82-42-259-1539

E-mail: Iskendo@hanmail.net

\begin{abstract}
Ki-Ho Lee ${ }^{1}$, Kyung-Jin $\mathrm{Jo}^{2}$, Ju-Young Kim³${ }^{3}$, Haing-Woon Baik', Seong-Kyu Lee ${ }^{1,4, *}$
'Department of Biochemistry-Molecular Biology, Eulji University School of Medicine, Daejeon; ${ }^{2}$ Department of Life Sciences, Pohang University of Science and Technology, Pohang; ${ }^{3} /$ maging Science-based Lung and Bone Diseases Research Center, Wonkwang University, Iksan; ${ }^{4}$ Department of Internal Medicine, Eulji University Hospital, Daejeon, Korea
\end{abstract}

Long-term 17beta-estradiol treatment protects against obesity, glucose intolerance and insulin resistance in obese and insulin-resistant ovariectomized rodents ${ }^{1-3}$, and long-term hormone therapy prevents diabetes mellitus due to alterations in body fat distribution and insulin sensitivity, but short-term hormone therapy does not provide complete protection in postmenopausal women. ${ }^{4,5}$

17beta-estradiol acts predominantly through genomic pathways and regulates the expression of a number of genes by binding to estrogen receptor $\alpha$ and $\beta .{ }^{6}$ However, the activation of non-genomic or rapid signaling pathways in response to 17 beta-estradiol has attracted increasing attention. ${ }^{7,8}$ Acute treatment ( $\leq 10$ minutes) with 17beta-estradiol rapidly increases the phosphorylation of Akt and AMPK, possibly through non-genomic effects, while it does not stimulate glucose uptake or enhance insulin sensitivity in skeletal muscles (rat soleus) ex vivo. ${ }^{9}$ We investigated whether 24 -hour treatment with 17 beta-estradiol stimulates glucose uptake and regulates the expression of genes associated with glucose metabolism through the genomic effects of estrogen receptor in $\mathrm{C} 2 \mathrm{C} 12$ myotubes. In this study, 24-hour treatment with 17beta-estradiol stimulated glu- cose uptake, but 30-minute treatment did not. We could not determine the potential mechanisms through which 17 beta-estradiol stimulated the expression of genes associated with glucose uptake in C2C12 myotubes, which was a limitation of the study. Further investigation of possible mechanisms will be needed.

As a reader mentioned, mitochondria may be associated with a potential mechanism by which 17 beta-estradiol treatment stimulates glucose uptake in $\mathrm{C} 2 \mathrm{C} 12$ myotubes, and $\mathrm{AMPK}$ stimulates mitochondrial biogenesis by regulating PGC-1 $\alpha$, which in turn promotes transcription of genes in mitochondria and the anti-oxidant defense system. ${ }^{10}$ We could not investigate these mechanisms. We postulate that $17 \mathrm{beta}$-estradiol regulates the expression of genes associated with glucose metabolism through the genomic effects of estrogen receptor in promoters of genes associated with glucose metabolism.

As a reader suggested, the role of estrogen in mitochondria, which is associated with glucose uptake in skeletal muscle, remains to be investigated, and measurement of the effects of estrogen on fatty acid oxidation in skeletal muscle would also be useful. We agree that 
these avenues of future research could provide insight into the mechanism of action of 17 beta-estradiol in glucose metabolism.

\section{CONFLICTS OF INTEREST}

The authors have no conflicts of interest to declare.

\section{REFERENCES}

1. Liu ML, Xu X, Rang WQ, Li YJ, Song HP. Influence of ovariectomy and 17beta-estradiol treatment on insulin sensitivity, lipid metabolism and post-ischemic cardiac function. Int $\mathrm{J}$ Cardiol 2004;97:485-93.

2. Saengsirisuwan V, Pongseeda S, Prasannarong M, Vichaiwong $\mathrm{K}$, Toskulkao C. Modulation of insulin resistance in ovariectomized rats by endurance exercise training and estrogen replacement. Metabolism 2009;58:38-47.

3. Riant E, Waget A, Cogo H, Arnal JF, Burcelin R, Gourdy P. Estrogens protect against high-fat diet-induced insulin resistance and glucose intolerance in mice. Endocrinology 2009; 150:2109-17.

4. Pentti K, Tuppurainen MT, Honkanen R, Sandini L, Kröger H,
Alhava E, et al. Hormone therapy protects from diabetes: the Kuopio osteoporosis risk factor and prevention study. Eur J Endocrinol 2009;160:979-83.

5. Richards L. Diabetes: Postmenopausal hormone therapy prevents diabetes. Nat Rev Endocrinol 2009;5:352.

6. Hewitt SC, Harrell JC, Korach KS. Lessons in estrogen biology from knockout and transgenic animals. Annu Rev Physiol 2005;67:285-308.

7. Levin ER. Rapid signaling by steroid receptors. Am J Physiol Regul Integr Comp Physiol 2008;295:R1425-30.

8. Prossnitz ER, Arterburn JB, Smith HO, Oprea TI, Sklar LA, Hathaway HJ. Estrogen signaling through the transmembrane G protein-coupled receptor GPR30. Annu Rev Physiol 2008; 70:165-90.

9. Rogers NH, Witczak CA, Hirshman MF, Goodyear LJ, Greenberg AS. Estradiol stimulates Akt, AMP-activated protein kinase (AMPK) and TBC1D1/4, but not glucose uptake in rat soleus. Biochem Biophys Res Commun 2009;382:646-50.

10.Jäger S, Handschin C, St-Pierre J, Spiegelman BM. AMP-activated protein kinase (AMPK) action in skeletal muscle via direct phosphorylation of PGC-1alpha. Proc Natl Acad Sci U S A 2007;104:12017-22. 